\title{
COVID-19 and people who use drugs: a call for action
}

\author{
Ehsan Jozaghi ${ }^{1,2}$ (D) Russ Maynard ${ }^{3} \cdot$ Dave Hamm $^{4} \cdot$ Samona Marsh $^{5,6,7,8}$
}

Received: 9 April 2020 / Accepted: 23 April 2020 / Published online: 13 May 2020

(C) The Canadian Public Health Association 2020, corrected publication 2020

\section{Dear Editor,}

In the past few months, the spread of COVID-19 around the world has highlighted how marginalization within the global health community can hinder an effective response (World Health Organization 2019). This has been evident in the longterm care homes in North Vancouver, British Columbia (BC), and elsewhere, when effective self-isolation measures fail (Woo 2020). However, we would like to raise concern about the state of social care and housing for marginalized people who use drugs and how COVID-19 could cause devastation if effective preventive measures fail to be implemented.

The recent evidence highlighting how the virus spreads and why its containment has been more challenging than the SARS outbreak 18 years ago raises significant concerns about the possible contamination within marginalized populations reliant on social services (Wilder-Smith et al. 2020). This is especially significant as many people who struggle under

This article was updated to correct the spelling of Dave Hamm's name.

Ehsan Jozaghi

ejozaghi@yahoo.com

1 The British Columbia Centre for Disease Control, 655 W 12th Ave, Vancouver, BC V5Z 4R4, Canada

2 School of Population and Public Health, University of British Columbia, 2206 East Mall, Vancouver, BC V6T 1Z3, Canada

3 PHS Community Services Society, 9 E Hastings St, Vancouver, BC V6A 1M9, Canada

4 Vancouver Area Network of Drug Users, 380 E Hastings St, Vancouver, BC V6A 1P4, Canada

5 Western Aboriginal Harm Reduction Society, 380 E Hastings St, Vancouver, BC V6A 1P4, Canada

6 The BC-Yukon Association of Drug War Survivors, 380 E Hastings St, Vancouver, BC V6A 1P4, Canada

7 Sex Workers United Against Violence, 334 Alexander St, Vancouver, BC V6A 1C3, Canada

8 Canadian Association of People Who Use Drugs, Vancouver, BC, Canada poverty and use drugs have compromised immune systems and chronic lung diseases such as chronic obstructive pulmonary disease, and the complications of diabetes are all too common among impoverished inner-city populations. The conditions for effective COVID-19 recovery are precarious to say the least due to unstable housing, homelessness, and a lack of social supports to facilitate care and sustenance. At the same time, the housing available for people who use drugs (PWUDs) often includes shared bathrooms, kitchens, and other facilities that could increase the risk of an outbreak if preventive measures are not considered. Living spaces are very small with few amenities so people often congregate. The challenges at public shelters do not need elucidating.

Therefore, we urge the three levels of government: city, state/provincial and federal, and the non-profit housing agencies to implement protective measures in shelters, social housing facilities, remand, and outreach centres to protect vulnerable and marginalized populations. Such protective measures should include regular testing, access to handwashing stations, interactive warning signs, gloves, masks, self-isolation for outreach workers who are sick, and proper sanitizations of shared kitchens. Similarly, we urge the health agencies to plan and find appropriate physical spaces for PWUDs when they become infected with COVID-19 because all of the protective measures listed above will be inefficient if infected PWUDs are left in shelters, homeless camps, or single room occupancy locations where other vulnerable people are also housed. The city of Victoria, BC, for example, passed an emergency resolution calling on the government in BC to use emergency powers to utilize empty hotels and motels for vulnerable homeless populations as a self-isolation measure during the COVID-19 pandemic (The Canadian Press 2020).

At the same time, we urge the health agencies to place appropriate measures in cases of quarantine so people who use drugs continue to have access to harm reduction services. Without an option that realistically acknowledges the fact that people who use drugs regularly interact to purchase maintenance amounts of illegal substances, efforts aimed at physical isolation will be undermined. Opiate agonist therapy (OAT) options and safe-supply can begin to address this challenge. In 
fact, not only has BC taken bold steps that would permit a physician to prescribe drugs as OATs for many illegal substances such as methamphetamines and heroin, but also the new guidelines allow pharmacies to deliver the OATs to PWUDs, so that the self-isolation measures can continue (Ling 2020).

Acknowledgements The editorial assistance of Caimen Yen is acknowledged in this letter. Also, many thanks to the board members of the Vancouver Area Network of Drug Users and Aiyanas Ormond.

\section{References}

Ling, J. (2020). BC will prescribe heroin alternatives to slow overdoses and COVID-19 exposure. In Vice news Accessed from: https:// www.vice.com/en_ca/article/pkek7g/a-vending-machine-incanada-is-dispensing-a-drug-twice-as-strong-as-heroin.

The Canadian Press. (2020). Victoria wants homeless to be housed in empty hotels during pandemic. The Vancouver Sun. Accessed from: https://vancouversun.com/news/local-news/victoria-wantshomeless-to-be-housed-in-empty-hotels-during-pandemic/.

Wilder-Smith, A., Chiew, C. J., \& Lee, V. J. (2020). Can we contain the COVID-19 outbreak with the same measures as for SARS? The Lancet Infectious Diseases. 20(5), e102-e107.

Woo, A. (2020). B.C. moves to tighten safety measures in long-care homes after COVID-19 deaths. The Globe \& Mail. Accessed from: https://www.theglobeandmail.com/canada/article-bc-moves-totighten-safety-measures-in-long-care-homes-after-covid/.

World Health Organization. (2019). Novel coronavirus (2019-nCoV): Situation report, 3 .

Publisher's note Springer Nature remains neutral with regard to jurisdictional claims in published maps and institutional affiliations. 